ACCEPTED MANUSCRIPT

\title{
Functional design of epoxy-based networks: tailoring advanced dielectrics for next-generation energy systems
}

To cite this article before publication: Istebreq Abdulla Hamad Saeedi et al 2019 J. Phys. D: Appl. Phys. in press https://doi.org/10.1088/1361$\underline{6463 / \mathrm{ab} 09 \mathrm{be}}$

\author{
Manuscript version: Accepted Manuscript \\ Accepted Manuscript is "the version of the article accepted for publication including all changes made as a result of the peer review process, \\ and which may also include the addition to the article by IOP Publishing of a header, an article ID, a cover sheet and/or an 'Accepted \\ Manuscript' watermark, but excluding any other editing, typesetting or other changes made by IOP Publishing and/or its licensors" \\ This Accepted Manuscript is @ 2019 IOP Publishing Ltd.
}

During the embargo period (the 12 month period from the publication of the Version of Record of this article), the Accepted Manuscript is fully protected by copyright and cannot be reused or reposted elsewhere.

As the Version of Record of this article is going to be / has been published on a subscription basis, this Accepted Manuscript is available for reuse under a CC BY-NC-ND 3.0 licence after the 12 month embargo period.

After the embargo period, everyone is permitted to use copy and redistribute this article for non-commercial purposes only, provided that they adhere to all the terms of the licence https://creativecommons.org/licences/by-nc-nd/3.0

Although reasonable endeavours have been taken to obtain all necessary permissions from third parties to include their copyrighted content within this article, their full citation and copyright line may not be present in this Accepted Manuscript version. Before using any content from this article, please refer to the Version of Record on IOPscience once published for full citation and copyright details, as permissions will likely be required. All third party content is fully copyright protected, unless specifically stated otherwise in the figure caption in the Version of Record.

View the article online for updates and enhancements. 


\title{
Functional design of epoxy-based networks:
} tailoring advanced dielectrics for next-generation energy systems

\author{
Istebreq A. Saeedi , Alun S. Vaughan and Thomas Andritsch \\ ${ }^{1}$ University of Southampton, School of Electronics and Computer Science, Tony Davies High Voltage \\ Laboratory, Southampton, SO17 1 BJ, United Kingdom
}

E-mail: iahs1e13@soton.ac.uk

Received xxxxxx

Accepted for publication $\mathrm{xxxxxx}$

Published xxxxxx

\begin{abstract}
Epoxy resins are widely used as the primary insulation material in many demanding energy-related applications. As such, the ability specifically to tailor the electrical performance of such systems to meet increasingly demanding insulation situations has considerable utility. This paper describes a new approach to this problem, which is based upon the controlled introduction of specific functional groups into the cured resin's network architecture. Here, two additives are considered, termed functional network modifiers, namely glycidyl hexadecyl ether and glycidyl 4-nonylphenyl ether; in all the investigated systems, the ideal stoichiometric ratio of epoxide groups to amine hydrogens is retained. In the case of both functional network modifiers, their inclusion resulted in a progressive reduction in the glass transition temperature $T_{g}$ of the system, a reduction in the real part of the permittivity and reduced dielectric losses wihin the accessible frequency range, increased DC conductivity and increased AC breakdown strength. The magnitude of the observed effects are found to be dependent upon the choice of functional modifier, which suggests that such changes are not related merely to the inclusion of an additive within the system, but are also influenced by the chemistry of the additive itself. Explanations for these effects are proposed. It is concluded that the use of such functional network modifiers at low concentrations ( $\sim \%$ in the work reported here) offers a novel alternative means of engineering advanced materials to meet the current and future needs in an adaptable and easily implemented manner.
\end{abstract}

Keywords: Epoxy Resin, functional network modifiers, dielectric properties,

\section{Introduction}

The materials used in high voltage electrical applications have been subject to progressive refinement since electrical power systems were first introduced in the nineteenth century. However, in recent decades, vast global research efforts have been devoted to exploring the potential of nano-technology as a means of actively designing new material systems for use in next generation power plant. Specifically, the concept is based upon ideas first articulated by Lewis in $1994 .{ }^{1}$ In his seminal paper, "Nanometric Dielectrics", Lewis speculated on the potential consequences of interfacial phenomena in multicomponent systems where phase dimension are small, such that local interfacial effects may markedly influence bulk macroscopic phenomena. Nanofillers may take many different forms and involve many different chemistries and, consequently, the inclusion of a nanofiller within a matrix material can affect many different properties. For example, the glass transition temperature $\left(T_{g}\right)$ of polymer nanocomposite was increased by the addition of carbon nanotubes (CNT), ${ }^{2}$ while the thermal conductivity of epoxy-based systems was enhanced by the introduction of graphene and graphene oxide nano-platelets, ${ }^{3-5}$ silver and aluminium nanoparticles, ${ }^{6}$ carbide derived nanowires, ${ }^{7}$ and layered clay nano-fillers. ${ }^{8}$ 
Many different electrical properties have also been examined in the broad context of nanocomposites. For example, the dielectric constant of an epoxy thermoset was modified by the incorporation of different oxides systems (titanium dioxide, $\mathrm{TiO}_{2}$, and barium titanate, $\left.\mathrm{BaTiO}_{3}\right),{ }^{9}, \quad{ }^{10}$ aluminium flakes, ${ }^{11}$ and nano-silica particles. $^{12}$

A key feature of the evolution of power systems has been a progressive increase in operating voltage, such that values in excess of $1 \mathrm{MV}$ now constitute a proven technology in some situations. As such, dielectric breakdown strength is an important parameter, since it provides an indication of a material's ability to withstand an applied electric field. In the case of epoxy resin, Zhe et al. reported that the dielectric breakdown strength of a nano-alumina $\left(\mathrm{Al}_{2} \mathrm{O}_{3}\right)$ filled epoxy resin was increased from $202 \mathrm{kV} / \mathrm{mm}$ to $212 \mathrm{kV} / \mathrm{mm}$ on addition of $5 \mathrm{wt}$.\% of this filler, ${ }^{13}$ while Preetha and Thomas ${ }^{14}$ reported that the inclusion of $5 \mathrm{wt} . \%$ of alumina increased the observed breakdown strength of their epoxy-based system by $25 \%$. Similar findings were reported by Li et al. ${ }^{15}$ Elsewhere, the breakdown strength of an epoxy nanocomposite containing $5 \mathrm{wt} . \%$ of nano-barium titanate was increased by $12 \% .{ }^{16}$ However, such beneficial effects of adding nanofillers are far from universal, with many other studies either reporting little effect ${ }^{17}$ or degraded performance. ${ }^{18}$ For example, a common explanation for reduced breakdown performance is nanoparticle agglomeration resulting from inadequate processing.

It is clear from the examples cited above that while the inclusion of nanofillers appears to have considerable promise, from a technological perspective, issues of reproducibility, quality assurance, scalability, etc., can be problematical. Ultimately, the fundamental mechanisms by which changes in breakdown strength are effected through the presence of nanofillers are poorly understood. In his 2004 paper, Lewis ${ }^{19}$ proposed that, in so-called nanodielectrics, interfacial interactions result in the formation of interphase zones whose properties differ from those of either bulk constituent and that, in the case of sufficiently small particles, the consequent interphase volume is sufficiently large that its properties markedly influence the overall behaviour of the system. While this paper failed to articulate any specifics about the interphase, this was addressed in subsequent work. Notably, Tanaka et al. proposed their multicore model, where interfacial regions were interpreted in terms of a number of zones where factors such as molecular dynamics, chain conformations and chemistry vary from place to place. ${ }^{20}$ While such a structural model has, in the intervening years, attracted broad acceptance, direct, quantitative verification is lacking. However, alternative hypotheses have more recently been proposed, which focus not directly on structural factors but, rather ascribe the influence of the nanofiller to the ways in which the local density of electronic states within the system is consequently modified. ${ }^{21,22}$ That is, changes in bulk electrical properties stem from changes in local electrical factors.

The work reported here set out to consider a possible corollary of the above, namely, that if the mechanisms by which nanoparticles influence the electrical response of nanocomposites is through changes in the local density of electronic states, it may be possible to engineer equivalent effects in alternative ways that do not involve the processing difficulties generally found when seeking to introduce nanoparticles into a polymeric host. Specifically, we sought to exploit a number of small molecular reactive moieties as a means of introducing functional groups into epoxy networks and, thereby, (a) modify the local density of electronic traps, which may be both physical and chemical in nature 23, 24 and (b) eliminate dispersion issues associated with the inclusion of nanoparticles. In general, molecular additives such as antioxidants, stabilisers, crosslinkers, clarifiers, voltage stabilisers, etc. have been included within polymeric systems as a means of modifying a wide range of different characteristics and, in the case of epoxy resins, network modification has been used as a means of varying mechanical properties. However, we are unaware of any previous work in which the introduction of covalently bonded functional groups into an epoxy network has been considered in detail, with a view to tailoring electrical properties. Here, two different so-called functional network modifiers (FNM) are considered, which were chosen based upon reports of the effectiveness of particular different labile compounds containing related functional groups as means of improving the high voltage performance of insulation systems based upon polyethylene.

\section{Experiment}

\subsection{Materials and sample preparation}

A diglycidyl ether of bisphenol A epoxy resin DER 332 was selected as the base epoxy resin and was used in concert with two FNMs, in order to vary the network structure of the final system. In the work reported here, the chosen modifiers are glycidyl hexadecyl ether (GHE) and glycidyl 4-nonylphenyl ether (GNPE) (see figure 1). The base resin and the modifiers were all obtained from Sigma Aldrich and were used as supplied. These compounds were used together with a commercial amine curing system, namely, Jeffamine D230, which was purchased from Huntsman. Although such a system is of less direct technological relevance than alternatives, this choice has the virtue of involving simple cure chemistry and a straightforward reaction stoichiometry. Modified amine and anhydride cured DGEBA resins have, however, been contrasted elsewhere ${ }^{25}$. The amine hydrogen equivalent weight of Jeffamine is $60 \mathrm{~g} \mathrm{~mol}^{-1}$. 
Table 1. Formulation of the reference and modified samples.

\begin{tabular}{cccc}
\hline Material System & $\begin{array}{c}\text { Resin } \\
(\mathrm{g})\end{array}$ & $\begin{array}{c}\text { FNM } \\
(\mathrm{g})\end{array}$ & $\begin{array}{c}\text { Hardener } \\
(\mathrm{g})\end{array}$ \\
\hline Neat Epoxy & 7.45 & 0.00 & 2.55 \\
1GHE & 7.33 & 0.13 & 2.54 \\
4GHE & 7.00 & 0.50 & 2.50 \\
10GHE & 6.37 & 1.21 & 2.43 \\
30GHE & 4.50 & 3.49 & 2.21 \\
1GNPE & 7.34 & 0.12 & 2.54 \\
4GNPE & 7.03 & 0.46 & 2.52 \\
10GNPE & 6.42 & 1.13 & 2.45 \\
30GNPE & 4.62 & 3.12 & 2.26 \\
\hline
\end{tabular}

The epoxide equivalent weight (EEW) of the DER 332 is 172-176 $\mathrm{g} \mathrm{mol}^{-1}$, while the EEW of the GHE and GNPE modifiers are $299 \mathrm{~g} \mathrm{~mol}^{-1}$ and $276 \mathrm{~g} \mathrm{~mol}^{-1}$, respectively.

To manufacture the samples, the resin was first preheated in a fan oven at $50{ }^{\circ} \mathrm{C}$ for $1 \mathrm{~h}$, to reduce its viscosity. Then, the weight of resin, modifier and hardener was calculated so as to ensure complete reaction of all the epoxide groups from both the resin and the functional network modifier with the amine hydrogens from the hardener; the required mass of each was then weighed out. The resin and functional network modifiers were first mixed together using a magnetic stirrer and, after 5 min of mixing, the hardener was added and mixing was continued for another $5 \mathrm{~min}$ before the resultant was degassed in a vacuum oven and introduced into a steel mould. Finally, the mould was placed in a fan oven, where the sample was left to cure for $2 \mathrm{~h}$ at $80^{\circ} \mathrm{C}$ and then postcured for $3 \mathrm{~h}$ at $125{ }^{\circ} \mathrm{C}$. The curing and post-curing processes used here were determined from a detailed optimisation investigation reported elsewhere. ${ }^{26}$ The produced samples, nominally $200 \mu \mathrm{m}$ in thickness, were stored in vacuum until use.

The modified systems contained 1-30 mol.\% of epoxide groups from the FNM and, therefore, a naming notation is used to refer to the samples based upon the molar percentage of epoxide groups and the relevant modifier. Thus, for example, 30GNPE refers to a system containing 30 mol.\% of epoxide groups from the GNPE modifier. The equivalent formulation for all systems in terms of the mass of each component is listed in Table 1. It is important to highlight that the FNMs considered here are both small molecules and, for most of the compositions reported, constitute a relatively minor mass fraction of the overall system. As such, their impact on viscosity and process-ability is minor, except for the systems in which 30 mol.\% of the epoxide groups are provided by the FNM.

\subsection{Measurements and characterisation}

The glass transition temperature of the produced samples was measured using differential scanning calorimetry (DSC). A Perkin-Elmer DSC7 was used,
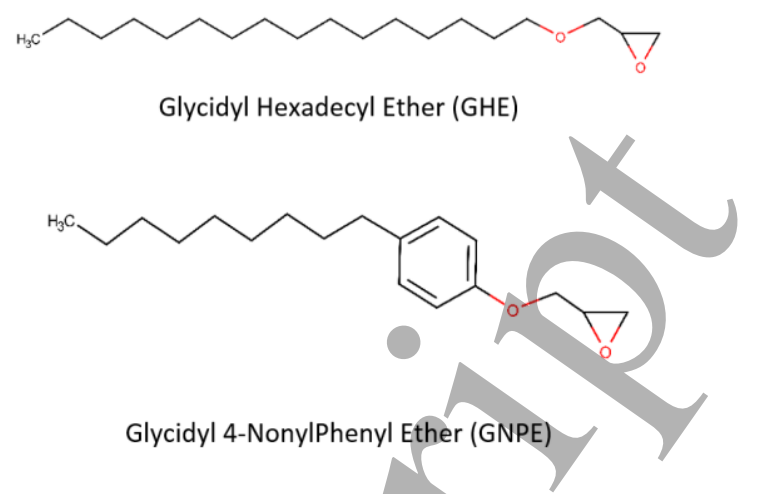

Figure 1. The chemical structure of the used epoxy-based reactive diluent.

which was routinely calibrated using high purity indium. For each sample, the thermal programme involved successive heating/cooling/heating cycles, all of which were conducted at a scan rate of $10{ }^{\circ} \mathrm{C} / \mathrm{min}$. The data reported here were obtained from the second heating scan, in all cases.

Thermogravimetric analysis (TGA) was used to study the thermal stability of the neat and modified samples. A PerkinElmer Pyris 1 TGA 7 was set to operate in a nitrogen environment at atmospheric pressure. About 5 $\mathrm{mg}$ of sample was placed in an aluminium can and the weight loss was measured over a temperature range from $50{ }^{\circ} \mathrm{C}$ to $600^{\circ} \mathrm{C}$ at a heating rate of $10^{\circ} \mathrm{C} / \mathrm{min}^{-1}$.

FTIR spectra of the manufactured samples were obtained using a Thermo-Scientific iD7 Nicolet iS5 Fourier transform infrared (FTIR) instrument, operating in attenuated total internal reflectance (ATR) mode. A background check was routinely conducted before examining any sample and the resulting data were normalised using the standard normal variate (SNV) method.

The dielectric behaviour of each system was investigated using an SI 1260 impedance/gain-phase analyser linked to a 1296 Solartron dielectric interface. Samples, nominally $200 \mu \mathrm{m}$ in thickness, were first sputter coated with a thin gold layer, to improve the electrical contact between the sample's surface and the electrodes. Each scan was conducted at $20{ }^{\circ} \mathrm{C}$, over a frequencies range of $10^{-1} \mathrm{~Hz}$ to $10^{6} \mathrm{~Hz}$ using an AC signal with an amplitude of $1 \mathrm{~V}$.

AC dielectric breakdown strength was measured using a Phenix Type $600 \mathrm{C}$ high voltage tester, according to the principles laid down in the ASTM D149-87 standard. The test cell contains two opposed spherical stainless steel electrodes, $6.32 \mathrm{~mm}$ in diameter, the sample was immersed in silicone oil and a $50 \mathrm{~Hz}$ AC voltage was applied to the specimen (nominally $200 \mu \mathrm{m}$ in thickness). The amplitude was increased at $500 \mathrm{~V} / \mathrm{s}$ until breakdown occurred. This process was repeated fifteen times for each material and the resulting data were processed assuming two-parameter Weibull statistics, with $90 \%$ confidence bounds. 
A simple two-probe test method was used to determine the DC conductivity of each system. For this, a test cell containing two parallel electrodes was used to subject the specimen to an applied field of $40 \mathrm{kV} / \mathrm{mm}$; again, the surface of the sample was sputter coated with gold, to ensure good specimen/electrode contact. The voltage was supplied from a standard DC power supply and the output current signal was measured as a function of time using a Keithley 485 current meter, which was connected to a computer. These measurements were conducted at $20{ }^{\circ} \mathrm{C}$ in accordance with the principles specified in the standard ASTM D257-07; the quoted values correspond to the average of the last one hundred measurement points obtained from three different samples of the same composition and the uncertainties correspond to the associated standard deviation.

\section{Results and discussion}

\subsection{GHE modified systems}

\subsubsection{FTIR Spectroscopy}

FTIR spectra from the accessible wavenumber range are shown in figure 2 . From figure $2 b$, which shows the spectral range from $2820 \mathrm{~cm}^{-1}$ to $2980 \mathrm{~cm}^{-1}$ in detail, it is evident that a new absorption peak at $2851 \mathrm{~cm}^{-1}$ appears in the modified systems, which increases in strength with increasing GHE content. In addition, the absorbance seen at $2927 \mathrm{~cm}^{-1}$ in the neat epoxy is progressively displaced to lower wavenumber and is increased in intensity as the fraction of GHE present in the system increases.

The spectral range from $3000 \mathrm{~cm}^{-1}$ to $2800 \mathrm{~cm}^{-1}$ is generally referred to as the $\mathrm{CH}$ stretching region and absorption in the range $2963 \mathrm{~cm}^{-1}$ to $2927 \mathrm{~cm}^{-1}$ is specifically associated with the antisymmetric stretch of $\mathrm{CH}_{3}$ and $\mathrm{CH}_{2}$, while the peaks at $2869 \mathrm{~cm}^{-1}$ and $2851 \mathrm{~cm}^{-}$ ${ }^{1}$ can be attributed to the symmetric stretch of $\mathrm{CH}_{3}$ and $\mathrm{CH}_{2} \cdot{ }^{27-31}$ Since the GHE modifier features a long chain alkyl group within its chemical structure which, ideally, comprises of sixteen $\mathrm{CH}_{2}$ groups and a single $\mathrm{CH}_{3}$ group, the addition of the GHE is expected to cause a significant increase in absorbance within the $\mathrm{CH}$ stretching region. The FTIR data shown above are therefore consistent with the integration of the GHE network modifier within the structure of the cured resin.

\subsubsection{Thermal Measurements of GHE-Modified Systems}

DSC data obtained from both the virgin epoxy and the various GHE-modified systems are provided in figure 3 and Table 2. In the latter, the indicated value of $T_{g}$ represents the inflection point temperature, $\Delta T_{g}$ is the temperature range over which the glass transition occurred, while $\Delta C_{p}$ represents the difference in the specific heat capacity of the material across $T_{g}$; the quoted uncertainties correspond to the standard deviation based upon three repeats. No glass transition was detectable for
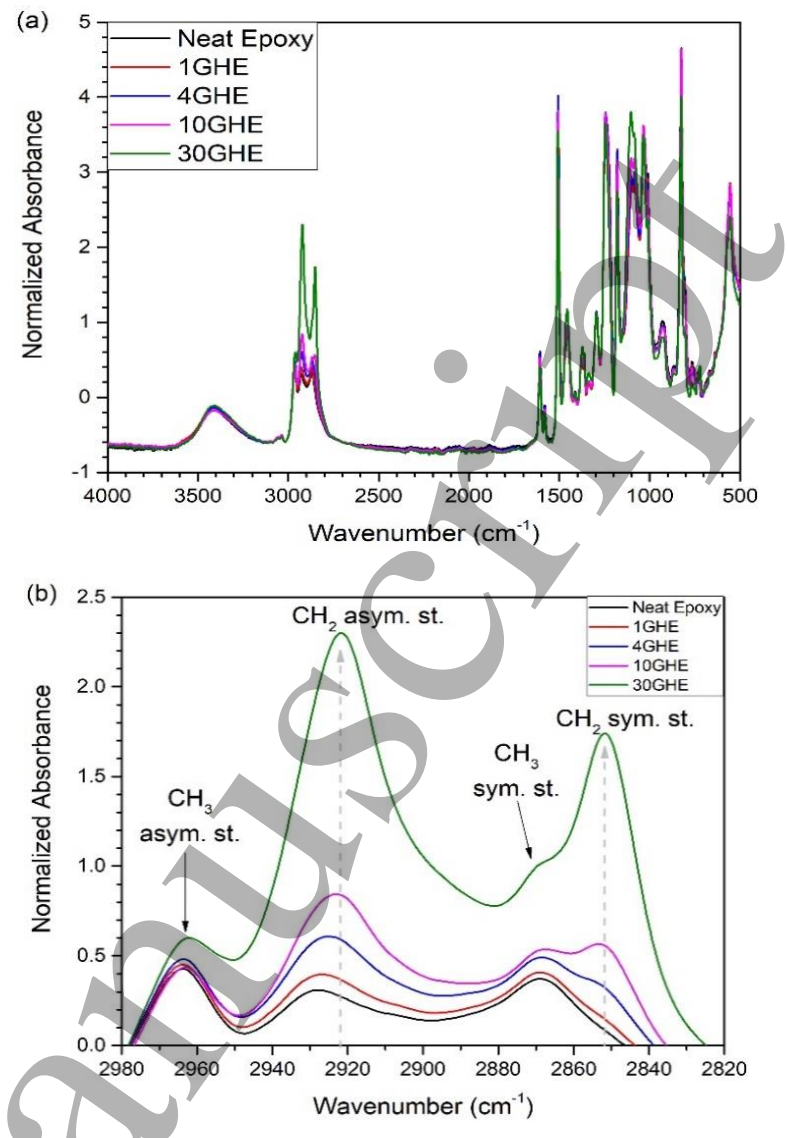

Figure 2. FTIR spectra of GHE modified DER 332 epoxy resin: (a) complete spectra and (b) FTIR spectra for wavenumber between $2980 \mathrm{~cm}^{-1}$ and $2820 \mathrm{~cm}^{-1}$.

30GHE, suggesting that its $T_{g}$ was below the temperature range that is accessible with our DSC; the data obtained from this material appear as a straight line in figure $3 \mathrm{a}$. From these data, it is evident that $T_{g}$ decreases with increasing GHE content, which is a consequence of reduced crosslink density (Table 1 indicates a progressive reduction in the required quantity of hardener) and additional free volume introduced into the system by the inclusion of the relatively long alkyl chains. ${ }^{32}$ These results are consistent with work reported by Liu et al. for epoxy resin systems modified using a functional network modifier containing a similar, but shorter, alkyl chain. ${ }^{33}$ Figure $3 \mathrm{~b}$ compares the TGA decomposition behaviour of the various systems, from which it is evident that inclusion of this FNM results in a monotonic displacement of the complete decomposition process to lower temperatures. This is reflected in a reduction in the onset of decomposition, from $334.3{ }^{\circ} \mathrm{C}$ for the neat epoxy to $279.2{ }^{\circ} \mathrm{C}$ for $30 \mathrm{GHE}$.

\subsubsection{Dielectric Spectroscopy Measurements of GHE- Modified Systems}

The real $\left(\varepsilon^{\prime}\right)$ and imaginary $\left(\varepsilon^{\prime \prime}\right)$ parts of the complex permittivity of the various GHE-modified systems are shown in figure 4 ; data obtained at $20{ }^{\circ} \mathrm{C}$. Consider, first, 

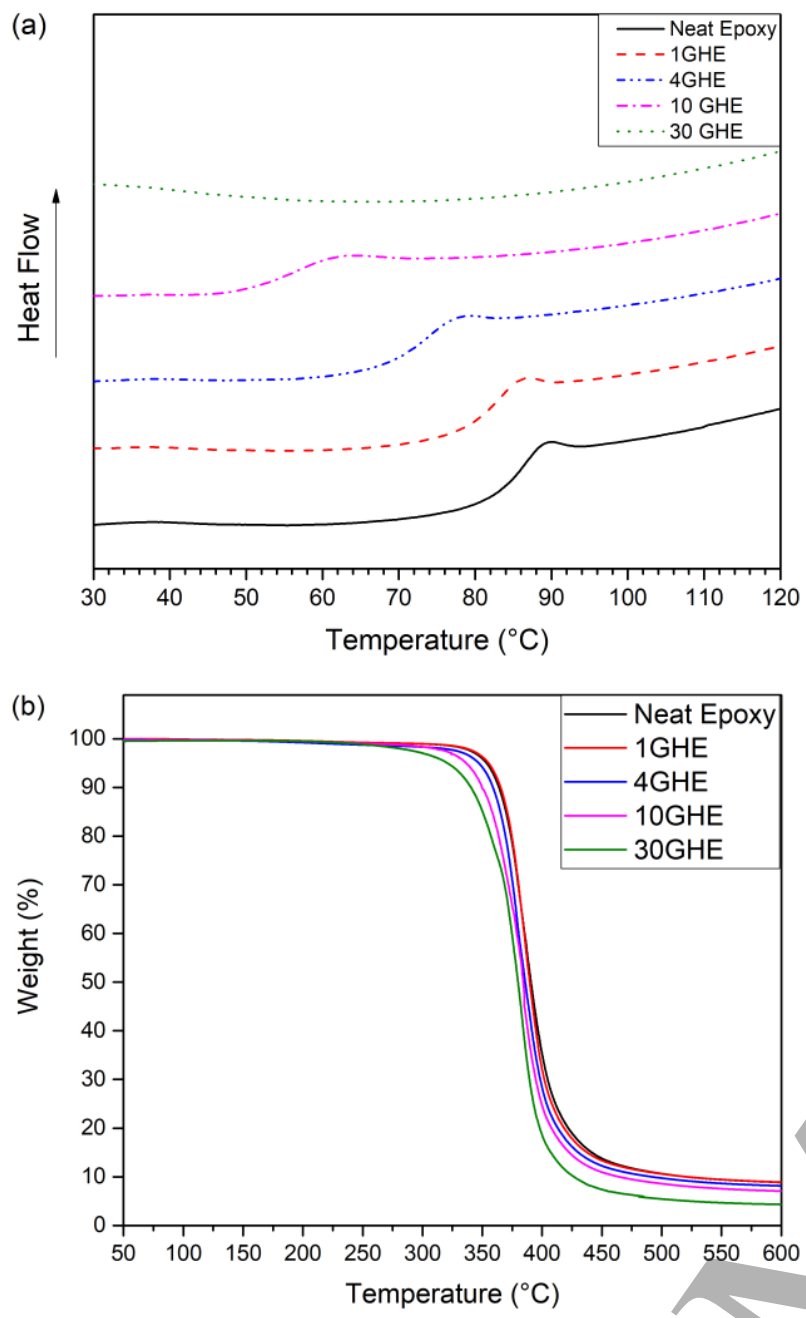

Figure 3. Thermal measurements for neat and GHE modified epoxy systems: (a) DSC measurements and (b) TGA data.

the variation of $\varepsilon^{\prime}$ with composition shown in figure $4 \mathrm{a}$, which reveals a progressive reduction in this quantity with increasing GHE content for all samples that, from figure 3 , are below $T_{g}$ at room temperature. This trend is consistent with the insertion of non-polar moieties into

Table 2. DSC data of GHE modified epoxy samples.

\begin{tabular}{|c|c|c|c|c|c|}
\hline & $\begin{array}{c}T_{g} \\
\left({ }^{\circ} \mathrm{C}\right)^{\mathrm{a}}\end{array}$ & $\begin{array}{l}\text { Onset } \\
\left({ }^{\circ} \mathrm{C}\right)^{\mathrm{b}}\end{array}$ & $\begin{array}{l}\Delta C_{p} \\
/\left(\mathrm{g} .{ }^{\circ} \mathrm{C}\right.\end{array}$ & $\begin{array}{l}\Delta T_{g} \\
\left({ }^{\circ} \mathrm{C}\right)\end{array}$ & $\begin{array}{c}1 \mathrm{wt} \% \\
\text { loss } \\
\left({ }^{0} \mathrm{C}\right)\end{array}$ \\
\hline $\begin{array}{c}\text { Neat } \\
\text { Epoxy }\end{array}$ & 85.3 & & & 4.4 & $\begin{array}{r}334.3 \\
\pm 0.4\end{array}$ \\
\hline 1GHE & 81.7 & & & 5.5 & $\begin{array}{r}332.9 \\
\pm 0.4\end{array}$ \\
\hline 4GHE & 71.5 & & 0.31 & 7.0 & $\begin{array}{l}314.7 \\
\pm 1.2\end{array}$ \\
\hline 10GHE & 54.2 & & 0.21 & 15.5 & $\begin{array}{r}302.1 \\
\pm 0.6\end{array}$ \\
\hline 30GHE & $\begin{array}{l}\text { Out of } \\
\text { range }\end{array}$ & $\begin{array}{l}\text { Out of } \\
\text { range }\end{array}$ & $\begin{array}{l}\text { Out of } \\
\text { range }\end{array}$ & $\begin{array}{l}\text { Out of } \\
\text { range }\end{array}$ & $\begin{array}{l}279.2 \\
\pm 0.8\end{array}$ \\
\hline
\end{tabular}

a) Error in $T_{g}= \pm 2{ }^{\circ} \mathrm{C}$; b) Error in onset $= \pm 0.2{ }^{\circ} \mathrm{C}$
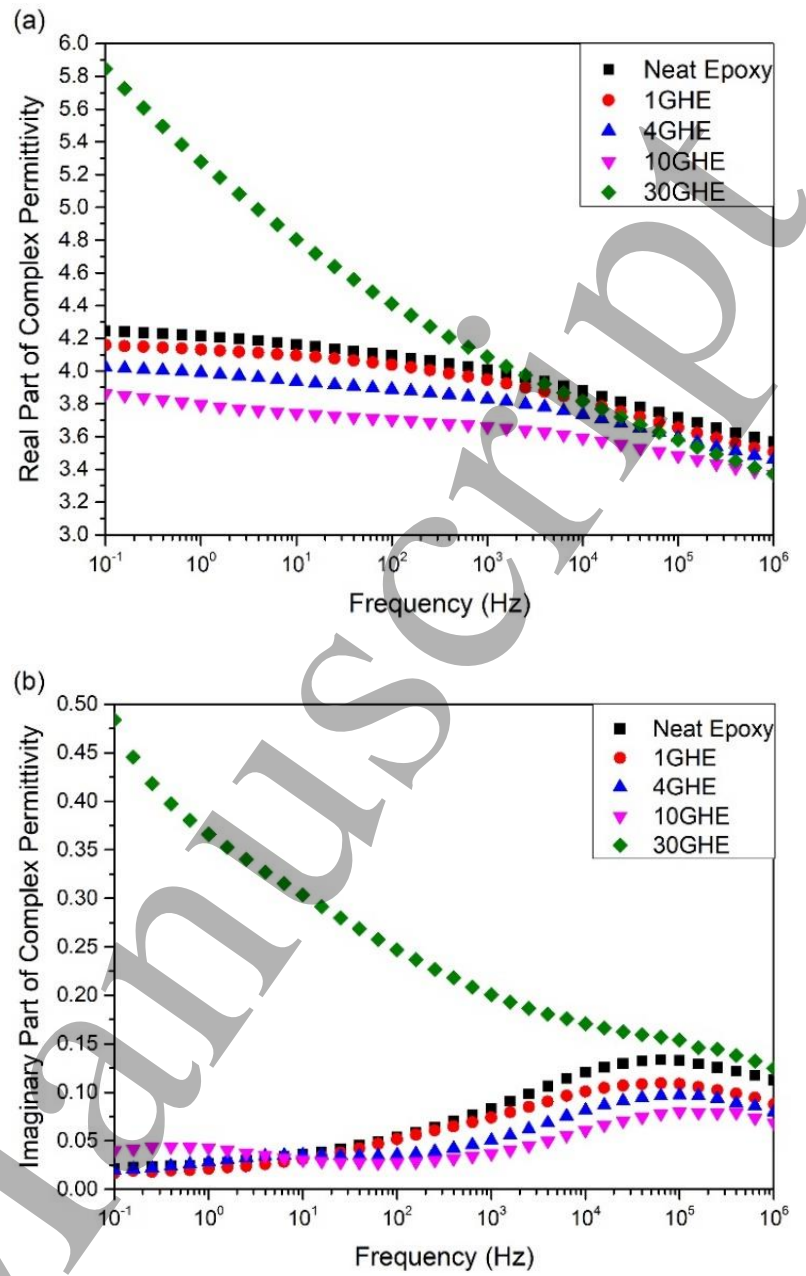

Figure 4. Complex permittivity of GHE modified epoxy resin samples obtained at $20^{\circ} \mathrm{C}$ : (a) real and (b) imaginary part.

the network. The frequency dependence of the real part of the relative permittivity of $30 \mathrm{GHE}$ is dominated by a marked increase in this quantity with decreasing frequency, a phenomenon that is often considered to be related to increased ionic conductivity below $T_{g} .{ }^{34}$

The data shown in figure $4 \mathrm{~b}$ contain a number of features that, again, can be related directly to molecular factors within each system. First, as the concentration of the GHE increases, the strength of the $\beta$-relaxation, which ranges in frequency from $\sim 100 \mathrm{~Hz}$ to above $10^{6} \mathrm{~Hz}$, progressively falls for all the samples that, from figure 3 , are below $T_{g}$ at room temperature. The observed progressive reduction in the strength of the $\beta$-relaxation with increasing GHE content is qualitatively consistent with both the composition of each system and the variations seen in $T_{g}$. Hydroxyl groups are formed during curing and the number of these should scale with the number of amine hydrogens present in the stoichiometry, assuming equivalent reaction efficiencies for all components. However, quantitative comparison of Table 1 and figure $4 b$, reveals that the apparent strength of the 
$\beta$-relaxation decreases to a greater extent than would be anticipated, based upon the composition of the various systems. This is in line with comparable work discussed in detail elsewhere ${ }^{35}$ and has been associated with changes in local constraints resulting from the integration of the FNM into the epoxy resin network. This displaces the associated relaxation towards higher frequencies: that is, broadens the relaxation peak outside our accessible range. Sample 10GHE also reveals evidence of a weak additional process below $1 \mathrm{~Hz}$. A complete analysis of the temperature dependence of this dielectric relaxation process is in ${ }^{36}$, which reveals this behaviour to be the $\alpha$ relaxation; its presence only in 10GHE is consistent with the relatively low DSC glass transition temperature of this formulation. ${ }^{37-39}$ For $30 \mathrm{GHE}$, the dominant feature in the frequency dependence of $\varepsilon$ "' is the marked increase in this quantity at lower frequencies, which is consistent with it being above $T_{g}$ at room temperature. As such, two factors are likely to contribute to this, namely conduction, which is conventionally associated with residual chloride ions ${ }^{34}$ , plus molecular motion above $T_{g}$. Of these factors, the frequency dependence suggests that the former is not dominant as far as these data are concerned.

\subsubsection{Conductivity of GHE-Modified Systems}

The measured DC conductivity values of epoxy resin samples containing different loadings of GHE functional network modifiers are presented in Table 3. These data suggest a monotonic increase electrical conductivity with increasing GHE content, albeit that the variation at low GHE content is small and comparable to experimental uncertainties. The maximum conductivity measured was found for the system where $30 \%$ of the epoxide groups were provided by the GHE modifier. A number of factors are likely to influence this. First, as noted above in connection with the dielectric results, exclusively in the case of $30 \mathrm{GHE}$, ionic conduction is likely to be a major contributing factor to the measured DC conductivity for systems that are above $T_{g}$; the conductivity of the neat epoxy resin was $\sim 10^{-17} \mathrm{~S} / \mathrm{cm}$, which was increased by 3 orders of magnitude for $30 \mathrm{GHE}$. Second, the introduction of the GHE modifier produces a network system containing alkyl

Table 3. DC conductivity and AC breakdown measurements of neat and GHE modified samples.

\begin{tabular}{|c|c|c|c|c|}
\hline Sample ID & $\begin{array}{c}\text { DC } \\
\text { Conductivity } \\
(\mathrm{S} / \mathrm{cm})\end{array}$ & $\begin{array}{l}\text { Weibull } \alpha \\
(\mathrm{kV} / \mathrm{mm})\end{array}$ & $\begin{array}{c}\text { Weibull } \\
\beta\end{array}$ & $\begin{array}{c}\% \\
\mathrm{BD}\end{array}$ \\
\hline Neat Epoxy & $\begin{array}{l}1.03 \times 10^{-17} \\
\pm 1.01 \times 10^{-18}\end{array}$ & $121.9 \pm 1.7$ & 26.6 & $100 \%$ \\
\hline $1 \mathrm{GHE}$ & $\begin{array}{l}1.36 \times 10^{-17} \\
\pm 1.04 \times 10^{-18}\end{array}$ & $124.1 \pm 2.2$ & 20.1 & $102 \%$ \\
\hline 4GHE & $\begin{array}{c}1.86 \times 10^{-17} \\
\pm 2.15 \times 10^{-18}\end{array}$ & $129.6 \pm 1.8$ & 24.6 & $106 \%$ \\
\hline $10 \mathrm{GHI}$ & $\begin{array}{l}3.82 \times 10^{-17} \\
\pm 9.12 \times 10^{-18}\end{array}$ & $119.5 \pm 1.5$ & 26.0 & $98 \%$ \\
\hline 30GHE & $\begin{array}{l}2.50 \times 10^{-14} \\
\pm 4.15 \times 10^{-15}\end{array}$ & $95.3 \pm 3.0$ & 11.9 & $78 \%$ \\
\hline
\end{tabular}

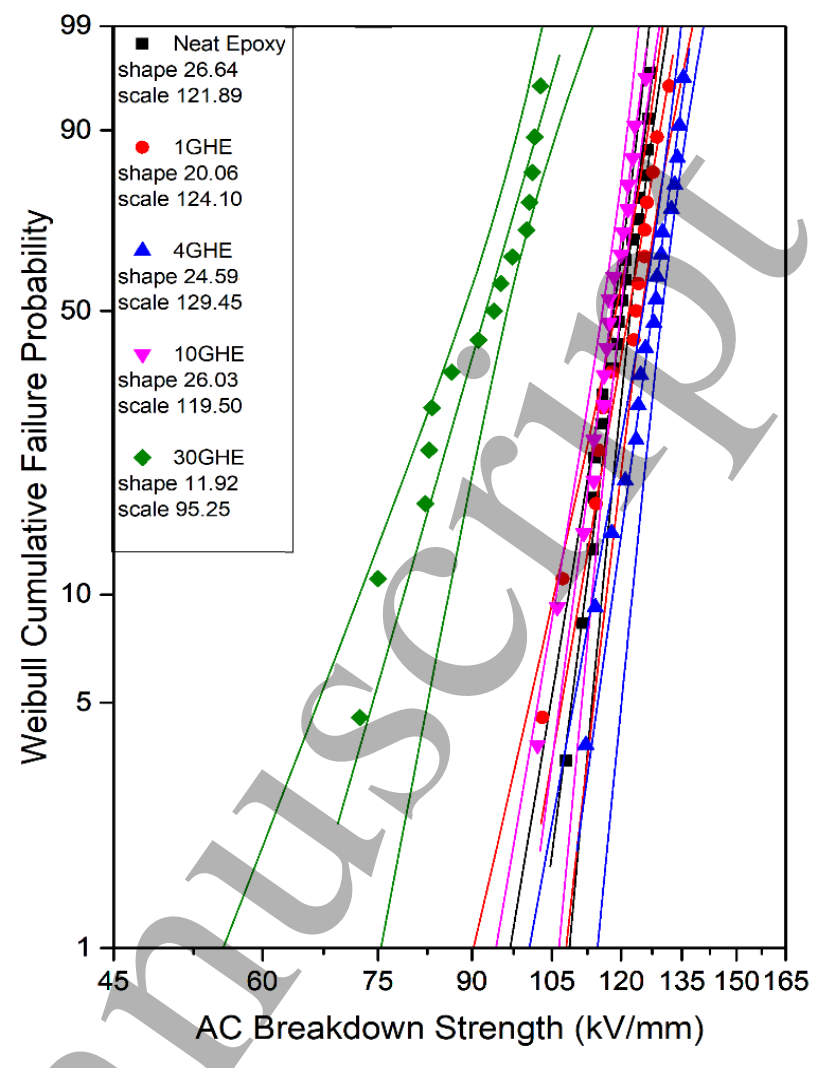

Figure 5. Weibull plot of breakdown data for neat and GHE modified epoxy resin.

branches which, based upon the observed reduction in $T_{g}$, leads to increased free volume. In case of polyethylene, where charge transport dynamics through disordered molecular conformations has been studied in details, the presence of localized regions of free volume has been shown to be an important factor in electronic conduction. ${ }^{40-42}$ Finally, the presence of GHE modifies the viscosity of the reacting system prior to vitrification; while the measured viscosity at $20{ }^{\circ} \mathrm{C}$ of the neat epoxy was $0.266 \pm\left(4 \times 10^{-4}\right) \mathrm{Pa} . \mathrm{s}$, this figure was reduced to $0.101 \pm\left(4 \times 10^{-4}\right)$ Pa.s for $30 \mathrm{GHE}$. As such, the presence of GHE would be expected to increase somewhat the efficiency of cross-linking, thereby affecting the residual unreacted end groups that remain within the network, another factor that has been shown to be important in determining the electrical behaviour of epoxy resins. ${ }^{35}$

\subsubsection{AC Breakdown Strength of GHE-Modified Systems} The breakdown behaviour of GHE-modified epoxy resin samples is shown in figure 5 and derived parameters are listed in Table 3 . These results indicate a progressive, but marginal, increase in the AC breakdown strength with GHE content from $0-4$ mol.\% of epoxide groups from the GHE modifier. Thereafter, the breakdown strength progressively drops with increasing GHE content; the marked drop in the breakdown strength of 30GHE may be related to the suppression of $T_{g}$ in this system and the consequent influence of ionic charge transport. The data 
presented above validate the assertion that underpins the work reported here in that they clearly demonstrate that it is possible to modify the network structure of an epoxy resin through the incorporation of functional groups (here, these are merely alkyl chains) and that this can be used to influence the electrical properties of the system. Although the precise mechanisms involved are not clear at this time, the effect of alkyl groups on the electrical properties of polymers have been considered in several studies. For example, Takahashi et al. patented dielectric polyolefin materials with a high resistance to electrical treeing, based on the voltage stabilizing properties of alkyl groups. ${ }^{43}$ Similarly, Hunt produced voltage stabilized polyolefins that contained alkyl groups as additives to control the electrical properties of the modified systems. ${ }^{44}$ Based on the work of Takahashi et al. and Hunt, Martinotto et al. manufactured voltage stabilizing additives that were used to increase the breakdown strength of crosslinked polyethylene in high voltage cables. ${ }^{45}$ All these studies were based on the assumption that terminal alkyl groups have the capability to donate/receive electrons, which allows the alkyl groups to control the electric field within the system to a certain extent. Therefore, it is possible that the increased breakdown strength of the GHE modified epoxy resin systems reported here is, similarly, a consequence of the introduced alkyl branches stabilizing the charge distribution in the system.

\subsection{GNPE Modified Systems}

The assertion that the improvement in breakdown performance seen in $4 \mathrm{GHE}$ is related, not merely to the inclusion of the functional network modifier, but is also determined by the chemistry of the functional modifier itself was tested by changing the chemistry of this component. Glycidyl 4-nonylphenyl ether (GNPE), like glycidyl hexadecyl ether, contains both an alkyl chain and an ether linkage but, in addition, also includes an aromatic ring.

\subsubsection{FTIR Spectroscopy of GNPE-Modified Systems}

The complete FTIR spectra obtained from neat and GNPE-modified epoxy resin samples is presented in figure 6a, while data from $2820 \mathrm{~cm}^{-1}$ to $2980 \mathrm{~cm}^{-1}$ are shown in more detail in figure 6b. From the latter, the peaks at wavenumbers $2964 \mathrm{~cm}^{-1}, 2927 \mathrm{~cm}^{-1}$ and $2869 \mathrm{~cm}^{-1}$ indicate increased absorbance as a function of GNPE functional network modifier. In addition, the absorbance peak at $2964 \mathrm{~cm}^{-1}$ is shifted to a lower wavenumber by the addition of GNPE. As an example, this peak is displaced to $2961 \mathrm{~cm}^{-1}$ in the case of $30 \mathrm{GNPE}$. As discussed above in connection with the GHE modified systems, the peaks at $2964 \mathrm{~cm}^{-1}, 2927 \mathrm{~cm}^{-1}$ and $2869 \mathrm{~cm}$ ${ }_{1}^{1}$ are located in the $\mathrm{CH}$ stretching region of the infrared spectrum. Specifically, the bands at $2964 \mathrm{~cm}^{-1}$ and 2927 $\mathrm{cm}^{-1}$ are associated with the antisymmetric stretch of $\mathrm{CH}_{3}$
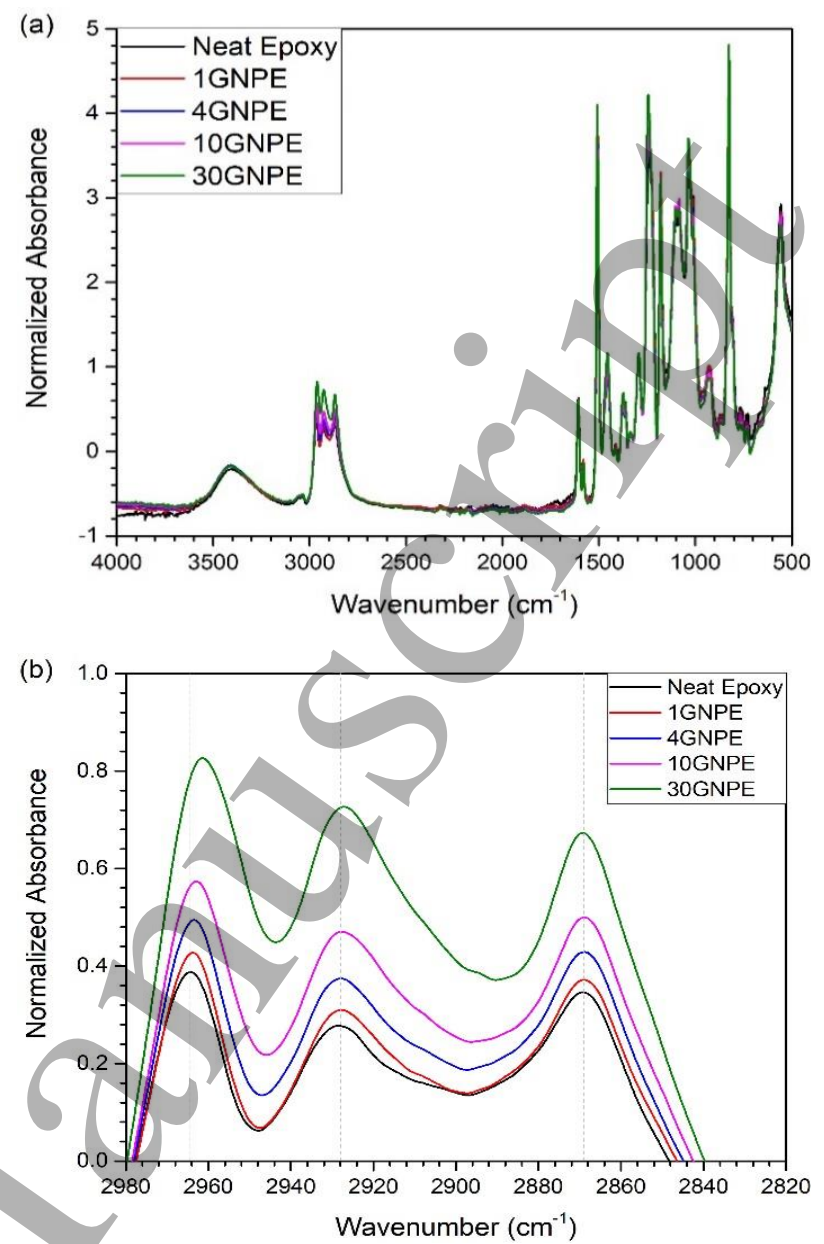

Figure 6. FTIR spectra of GNPE modified DER 332 epoxy resin: (a) complete spectra and (b) FTIR spectra for wavenumber between $2980 \mathrm{~cm}^{-1}$ and $2820 \mathrm{~cm}^{-1}$.

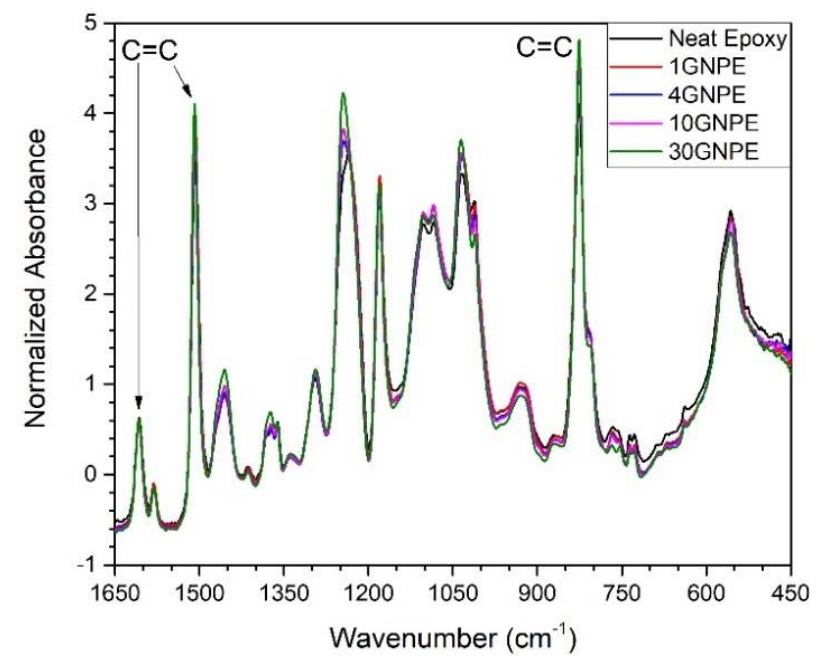

Figure 7. FTIR spectra of neat epoxy and GNPE modified samples for wavenumber between $1650 \mathrm{~cm}^{-1}$ and $450 \mathrm{~cm}^{-1}$.

and $\mathrm{CH}_{2}$ groups, while the peak at $2869 \mathrm{~cm}^{-1}$ is related to the symmetric stretch of $\mathrm{CH}_{3} .{ }^{27}$ Since the added functional modifier includes an aliphatic chain with 
chemical structure $\left(\mathrm{CH}_{2}\left(\mathrm{CH}_{2}\right)_{7} \mathrm{CH}_{3}\right)$, the three peaks present in figure $6 \mathrm{~b}$, which increase in strength with increasing GNPE content, are again, reasonably associated with the aliphatic part of the GNPE modifier. However, since the GNPE modifier also contains a benzene ring within its chemical structure, it may not be appropriate to associate these peaks exclusively with the aliphatic part of the GNPE, since it has been reported that the stretching band of the carbon/carbon bonds in the aromatic structure might also be located in this range. ${ }^{27}$ Infrared absorption in para disubstituted benzene rings appears as a very strong sharp peak in the range $860 \mathrm{~cm}^{-1}$ - $800 \mathrm{~cm}^{-1}$, while the skeletal ring breathing modes are located at $1600 \mathrm{~cm}^{-1}, 1500 \mathrm{~cm}^{-1}$ and $1450 \mathrm{~cm}^{-1} \cdot 27,46$ These peaks can be seen in figure 7 , which shows the FTIR spectra of GNPE modified samples for wavenumbers between $1650 \mathrm{~cm}^{-1}$ and $450 \mathrm{~cm}^{-1}$. This figure indicates the appearance of the peaks associated with the aromatic structure, which are indicated $\mathrm{C}=\mathrm{C}$. However, since these peaks appear in the so-called figure-print region of the spectrum, precise association of these with specific functional groups is problematical. Nevertheless, analysis of the observed variations in the FTIR spectra with composition provides compelling evidence for the integration of the GNPE functional modifier within the structure of the epoxy resin.

\subsubsection{Thermal Measurements of GNPE-Modified Systems} The effect of the addition of GNPE functional network modifiers on the glass transition behaviour of DER332 epoxy resin is shown in figure $8 \mathrm{a}$ and listed in Table 4. From these data, it is evident that the measured value of $T_{g}$ decreases with increasing functional network modifier content such that while $T_{g}$ for the neat epoxy was $85.3{ }^{\circ} \mathrm{C}$, this was reduced to $42.5{ }^{\circ} \mathrm{C}$ by the addition of $30 \%$ of epoxide groups from the GNPE. This decrease parallels that reported above for GHE, because the inclusion of GNPE would similarly affect the network architecture and free volume present in the system. ${ }^{47-49}$ These finding are in line with work by Bakar et al., who also reported a drop in $T_{g}$ on inclusion of a comparable moeity. ${ }^{50}$ Figure $8 \mathrm{~b}$ compares the TGA decomposition behaviour of the various systems. While the onset of degradation progressively falls with inclusion of GNPE, as for GHE (c.f. Tables 2 and 4), subsequent decomposition is less composition dependent, which may be related to the presence of the aromatic character of GNPE.

\subsubsection{Dielectric Spectroscopy Measurements of GNPE-} Modified Systems

The general trend in the real part of the complex permittivity of samples modified with GHE and GNPE indicates that as the fraction of epoxide groups supplied by the functional network modifier increases, the permittivity decreases, as shown in figure $9 a$. Figure $9 b$ shows the effect of GNPE concentration on $\varepsilon^{\prime \prime}$, in which,
Table 4. DSC data of GNPE modified epoxy samples.

\begin{tabular}{|c|c|c|c|c|c|}
\hline & $\begin{array}{c}T_{g} \\
\left({ }^{0} \mathrm{C}\right)^{\mathrm{a}}\end{array}$ & $\begin{array}{l}\text { Onset } \\
\left({ }^{0} \mathrm{C}\right)^{\mathrm{b}}\end{array}$ & $\begin{array}{c}\Delta C_{p} \\
\left(\mathrm{~J} /\left(\mathrm{g} \cdot{ }^{0} \mathrm{C}\right)\right.\end{array}$ & $\begin{array}{l}\Delta T_{g} \\
\left({ }^{0} \mathrm{C}\right)\end{array}$ & $\begin{array}{l}1 \mathrm{wt} \% \\
\text { loss at } \\
\mathrm{T}\left({ }^{\circ} \mathrm{C}\right)\end{array}$ \\
\hline $\begin{array}{l}\text { Neat } \\
\text { Epoxy }\end{array}$ & 85.3 & 83.3 & 0.34 & & $\begin{array}{r}334.3 \\
\pm 0.4\end{array}$ \\
\hline $1 \mathrm{GNPE}$ & 76.8 & 74.5 & 0.34 & & \\
\hline 4 GNPE & 75.0 & 72.7 & 0.3 & & $\begin{array}{l}328.2 \\
\pm 0.4\end{array}$ \\
\hline 10 GNPE & 64.4 & 61.9 & & & 95.9 \\
\hline 30 GNPE & 42.5 & 39.2 & 0.27 & & $\begin{array}{l}280.1 \\
\pm 0.9\end{array}$ \\
\hline
\end{tabular}
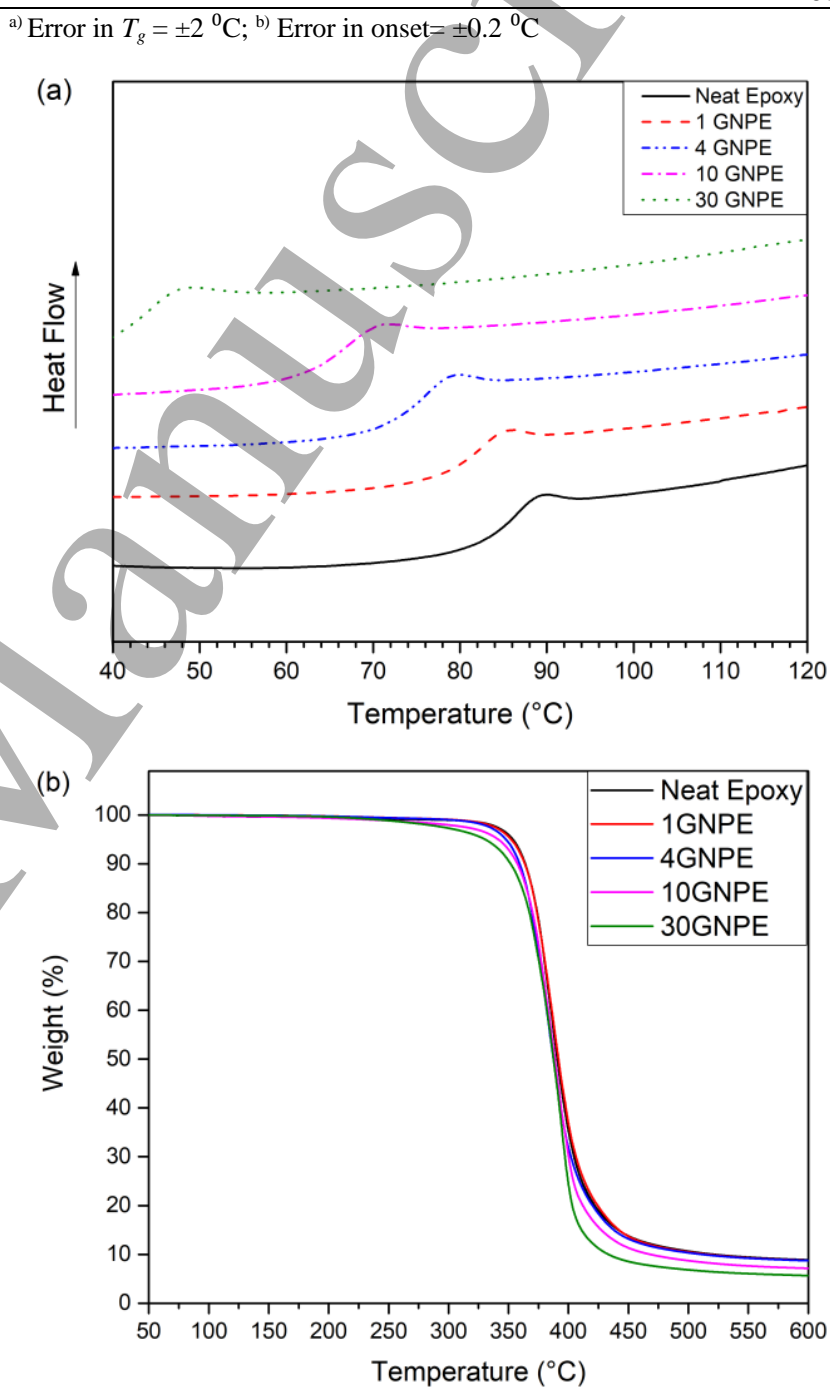

Figure 8. Thermal measurements for neat and GNPE modified epoxy systems: (a) DSC data and (b) TGA data.

only the $\beta$-relaxation around $10^{5} \mathrm{~Hz}$ can be seen. As discussed above, this peak is associated with the movement of the hydroxyl groups in epoxy resin system, which are generated during the curing process. ${ }^{51,52}$ The introduction of GHE and GNPE reduces the strength of the observed dielectric $\beta$-relaxation, which could be a direct result of a reduction in the crosslink density and/or 
(a)

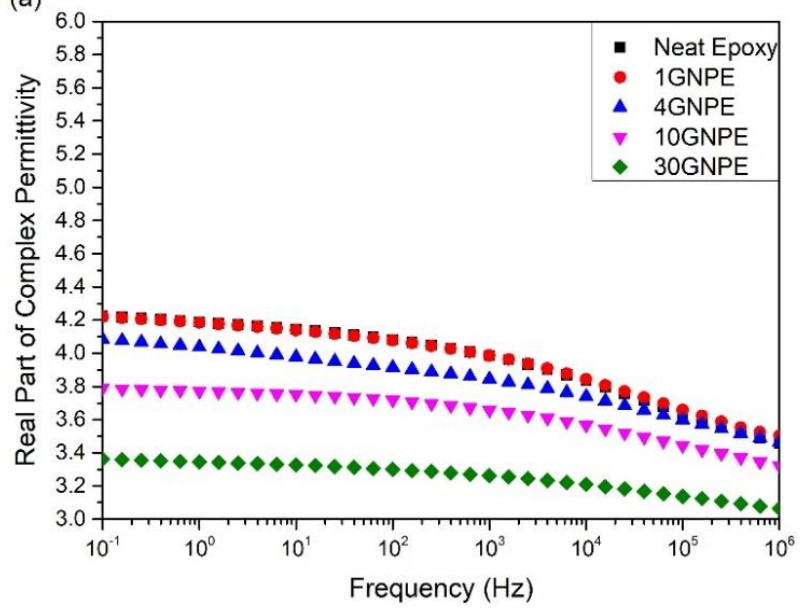

(b)

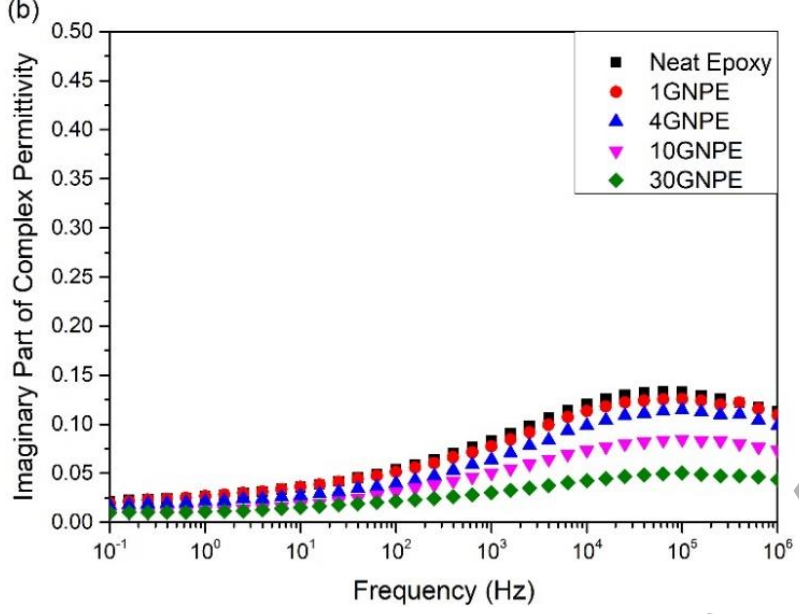

Figure 9. Complex permittivity of GNPE modified epoxy resin samples obtained at $20^{\circ} \mathrm{C}$ for: (a) real and (b) imaginary part.

the presence of excess free volume displacing the $\beta$ relaxation to higher frequencies. This effect has been reported elsewhere, when the use of non-stoichiometric epoxy formulations resulted in a less heavily cross-linked structure being formed. ${ }^{35}$

\subsubsection{Conductivity of GNPE-Modified Systems}

The effect of GNPE inclusion on DC conductivity was investigated. From Table 5, it is evident that, as with GHE, the introduction of GNPE results in a monotonic increase in the measured conductivity, albeit that the variation at low GNPE contents is small and comparable to experimental uncertainties. Here, the conductivity of 30GNPE is about one order of magnitude greater than that of the neat epoxy. While similar explanations can be proposed to those provided above for the systems containing GHE, the fact that all of the formulations based upon GNPE are below $T_{g}$ at room temperature explains both the absence of any low frequency dielectric loss processes for these materials and the absence of a marked jump in conductivity in 30GNPE (no contribution
Table 5. DC conductivity and AC breakdown measurements of neat and GNPE modified samples.

\begin{tabular}{|c|c|c|c|c|}
\hline Sample ID & $\begin{array}{c}\text { DC } \\
\text { Conductivity } \\
(\mathrm{S} / \mathrm{cm})\end{array}$ & $\begin{array}{l}\text { Weibull } \alpha \\
(\mathrm{kV} / \mathrm{mm})\end{array}$ & $\begin{array}{c}\text { Weibull } \\
\beta\end{array}$ & $\begin{array}{c}\% \\
\mathrm{BD}\end{array}$ \\
\hline Neat Epoxy & $\begin{array}{c}1.03 \times 10^{-17} \\
\pm 1.01 \times 10^{-18}\end{array}$ & $121.9 \pm 3$ & & $\%$ \\
\hline $1 \mathrm{GNPE}$ & $\begin{array}{c}1.22 \times 10^{-17} \\
\pm 2.40 \times 10^{-17}\end{array}$ & & & $110 \%$ \\
\hline 4 GNPE & $\begin{array}{c}4.08 \times 10^{-17} \\
\pm 1.50 \times 10^{-17}\end{array}$ & & & $11 \%$ \\
\hline 10GNPE & $\begin{array}{c}1.40 \times 10^{-16} \\
\pm 7.42 \times 10^{-17}\end{array}$ & 133.9 & & $110 \%$ \\
\hline 30GNPE & $\begin{array}{r}2.22 \times 10^{-16} \\
\pm 8.93 \times 10^{-17} \\
\end{array}$ & & 20.8 & $110 \%$ \\
\hline
\end{tabular}

from ionic conduction). In short, with this proviso, the data presented in Table 3 and Table 5 are entirely consistent.

\subsubsection{AC Breakdown Strength of GNPE-Modified Systems}

Figure 10 and Table 5 contain AC breakdown strength data obtained from the various GNPE-modified epoxy resin systems. From these, it is evident that the addition of GNPE can result in an increase in the breakdown strength of the systems and that, compared with the GHE-based systems described above, the increase is greater. For example, the Weibull $\alpha$ parameter of neat epoxy resin is $121.9 \mathrm{kV} / \mathrm{mm} \pm 3.4$ $\mathrm{kV} / \mathrm{mm}$; the breakdown strength of $4 \mathrm{GNPE}$ is $135.3 \mathrm{kV} / \mathrm{mm} \pm$ $2.4 \mathrm{kV} / \mathrm{m}$ m (the breakdown strength of $4 \mathrm{GHE}$ was previously reported to be $129.6 \mathrm{kV} / \mathrm{mm} \pm 1.8 \mathrm{kV} / \mathrm{mm})$. Also, in marked contrast to the data shown in Table 3, Table 5 clearly demonstrates that the improvement in breakdown performance caused by inclusion of GNPE is not strongly dependent on GNPE content, with all modified systems outperforming the neat epoxy. While an increase in breakdown strength of $\sim 10 \%$ may be considered small, elsewhere 53, 54, comparable increases in high field performance have been shown to translate into much greater benefits under technologically relevant electric fields.

This beneficial effect of aromatic structures on breakdown strength has previously been reported in connection with the inclusion of voltage stabilizers within polyethylene. Martinotto et al. manufacture a material with voltage stabilizing capabilities by using an aromatic structure (benzophenone) attached to an alkyl group. ${ }^{45}$ Similarly, Englund et al. ${ }^{55}$ and Jarvid et al. ${ }^{56}$ stated that aromatic rings attached to alkyl groups increase the breakdown strength of the host insulating material. In this work, the increased breakdown strength was suggested to be due to two factors namely, the difference between the ionisation potential of the added aromatic-alkyl molecules compared to that of the host material and the high electron affinity of such structures, which would allow aromatic-alkyl moieties to act as voltage stabilizers within the system. ${ }^{56,57}$ While we are not aware of 


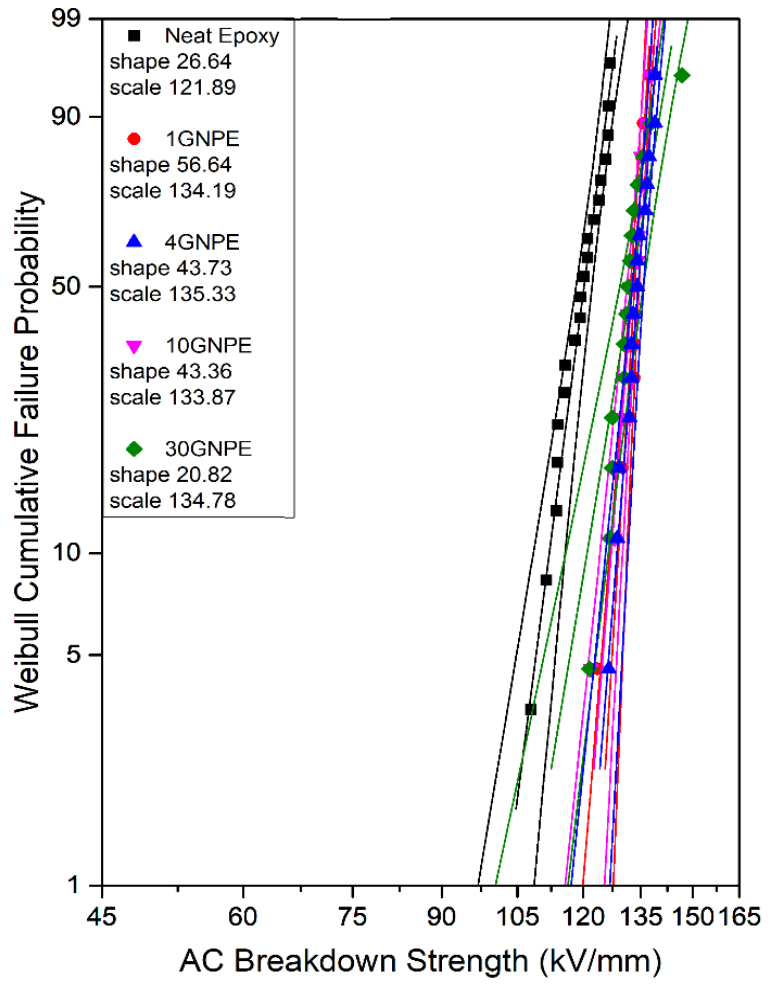

Figure 10. Weibull plot of breakdown data for neat and GNPE modified epoxy resin.

any theoretical studies of charge transport through epoxy resins, this is not the case for analogues of polyethylene, where the role of both chemical and structural factors have been considered ${ }^{24,58-60}$. In the latter case, the importance of free volume on electron transport has been demonstrated and, therefore, in addition to the direct role of the functional groups of the FNM, the impact of such species on local structure and, thereby, charge transport dynamics may also be significant. Since the GNPE modifier used here contains a terminal alkyl group attached to an aromatic ring, it has similarities to the voltage stabilizers used by Jarvid et al. and described by Martinotto et al. ${ }^{45,57}$ Therefore, the increased breakdown strength values shown in Table 5 could have a similar origin to the positive effects reported in such studies.

\section{Conclusions}

The thermal and electrical properties of two modified epoxy resin systems have been described. These systems were formulated using two epoxy-based functional network modifiers, which were used to adjust the network architecture while maintaining an ideal stoichiometric ratio of epoxide groups and amine hydrogens. The functional network modifiers considered here, namely glycidyl hexadecyl ether and glycidyl 4-nonylphenyl ether, respectively feature an aliphatic chain and an aliphatic chain combined with an aromatic ring. Increased infrared absorption at wavenumbers characteristic of these functional groups was taken to indicate successful incorporation of the functional network modifiers into the cured systems. In both cases, the inclusion of the functional network modifiers resulted in a progressive reduction in the glass transition temperature of the system, a reduction in the real part of the permittivity, reduced dielectric losses, increased DC conductivity and increased AC breakdown strength. The magnitude of the observed effects was found to be dependent upon the choice of functional network modifiers, which suggests that such changes are not related merely to the inclusion of a functional network modifiers into the system, but are also influenced by the chemistry of the functional network modifier itself.

While a comparable strategy has been used previously as a means of modifying the mechanical properties of epoxy resins, this is to our knowledge the first time that this general approach has been considered in detail as a means of introducing particular functional groups into a thermosetting polymer with a yiew actively to tailoring its electrical parameters. In the case of the GHE and GNPE considered here, the reported reduction in $\varepsilon^{\prime}$ is not unexpected, given the presence of the alkyl chain in both systems. However, the observed increases in breakdown strength are not intuitively obvious but, we feel, are significant. The value of being able to tailor at the molecular level the macroscopic properties of insulation systems to meet ever more demanding technological requirements is well appreciated and has fuelled a vast amount of associated research over recent decades, notably in connection with the development of so-called nanodielectrics. While the nanodielectric concept has undoubted value, examination of published literature reveals problems associated with reliable and scalable processing, quality control, reproducibility, etc. The use of functional network modifiers at low concentrations ( $\sim \%$ in the work reported here) appears to offer a novel alternative means of engineering advanced materials to meet current and future needs in a simplistic and adaptable manner, where they could be regarded as additives to enhance existing established resin systems. However, we accept that the functional network modifiers reported here are not optimal. The aim of this paper is merely to demonstrate the validity of the concept optimisation, consideration of the generality of the effects reported and further validation of this concept in terms of different resin systems, curing systems and different functional network modifiers will be published in due course.

\section{Acknowledgements}

The authors would like to thank the Schlumberger Foundation Faculty for the Future for the financial support. We would also like to thank Mrs Allison V. Shaw for her help with measuring the Fourier transform infrared spectroscopy of the samples. 


\section{References}

1. T. Lewis, IEEE Trans. Dielectr. Electr. Insul., 1994, 1, 812-825.

2. H. Gu, S. Tadakamalla, X. Zhang, Y. Huang, Y. Jiang, H. A. Colorado, Z. Luo, S. Wei and Z. Guo, J. Mater. Chem. C, 2013, 1, 729-743.

3. L.-Z. Guan, Y.-J. Wan, L.-X. Gong, D. Yan, L.-C. Tang, L.-B. Wu, J.-X. Jiang and G.-Q. Lai, J. Mater. Chem. A, 2014, 2, 15058-15069.

4. J. Wei, T. Vo and F. Inam, RSC Advances, 2015, 5, 73510-73524.

5. X. Qian, L. Song, B. Yu, B. Wang, B. Yuan, Y. Shi, Y. Hu and R. K. Yuen, J. Mater. Chem. A, 2013, 1, 6822-6830.

6. Y. Y. Sun, Z. Q. Zhang, K. S. Moon and C. P. Wong, J. Polym. Sci. Part B: Polym. Phys., 2004, 42, 38493858.

7. S. Vaisakh, K. Mahesh, S. Balanand, R. Metz, M. Hassanzadeh and S. Ananthakumar, RSC Advances, 2015, 5, 16521-16531.

8. O. Becker, R. Varley and G. Simon, Polymer, 2002, 43, 4365-4373.

9. J. Nelson and Y. Hu, J. Phys. D: Appl. Phys., 2005, 38, 213 - 222.

10. G. Belijar, S. Diaham, Z. Valdez-Nava and T. Lebey, J. Phys. D: Appl. Phys., 2015, 49, 045501.

11. Z. Elimat, A. Zihlif and G. Ragosta, J. Phys. D: Appl. Phys., 2008, 41, 165408.

12. Y. Li, M. Tian, Z. Lei and J. Zhang, J. Phys. D: Appl. Phys., 2018, 51, 125309

13. O. K. Zhe L, Ohki Y, Tanaka T, Proc. Int. Conf. Prop. Appl. Dielectr. Mater., 9th, 2009, 753-756.

14. P. Preetha and M. J. Thomas, IEEE Trans. Dielectr. Electr. Insul., 2011, 18.

15. Z. Li, G. Sheng, X. Jiang and T. Tanaka, IEEJ Trans. Electr. Electron. Eng., 2017, 12.

16. S. Siddabattuni, T. P. Schuman and F. Dogan, Mater. Sci. Eng., B, 2011, 176, 1422-1429.

17. S. Singha and M. J. Thomas, IEEE Trans. Dielectr. Electr. Insul., 2008, 15.

18. T. Imai, F. Sawa, T. Ozaki, Y. Inoue, T. Shimizu and T. Tanaka, IEEE Conf. Electr. Insul. Dielectr. Phenom., 2006, 306-309.

19. T. Lewis, IEEE Trans. Dielectr. Electr. Insul., 2004 11, 739-753.

20. T. Tanaka, M. Kozako, N. Fuse and Y. Ohki, IEEE Trans. Dielectr. Electr. Insul., 2005, 12, 669-681.

21. S. Li, D. Min, W. Wang and G. Chen, IEEE Trans. Dielectr. Electr. Insul., 2016, 23, 2777-2785.

22. T. Tanaka, IEEE Conf. Electr. Mater. Power. Equip.,1st, 2017, 61-64.

23. D. Cubero and N, Quirke, J. Chem. Phys., 2004, 120, $7772-7778$.

24. M. Meunier and N. Quirke, J. Chem. Phys., 2000, 113, 369-376.

25. I. A. Saeedi, T. Andritsch, A. S. Vaughan and D. J. Salter, 2018.
26. I. A. Saeedi, A. S. Vaughan, T. Andritsch and S. Virtanen, IEEE Conf. Electr. Insul. Dielectr. Phenom., 2016, 461-464.

27. J. Lambert, H. Shurvell, D. Lightner and R. Cooks, Organic Structural Spectroscopy Prentice Hall London, UK, 1998.

28. G. Nikolic, S. Zlatkovic, M. Cakic, S. Cakic, C. Lacnjevac and Z. Rajic, Sensors, 2010, 10, 684-696.

29. H. Alamri and I. M. Low, Polym. Test., 2012, 31, 810-818

30. P. Pasbakhsh, H. Ismail, M. A. Fauzi and A. A. Bakar, Appl. Clay Sci., 2010, 48, 405-413.

31. J. Lambert, Organic structural analysis, Macmillan Pub Co, Michigan, USA, 1976.

32. C. A. Daniels, Polymers: structure and properties, CRC Press, Pennsylvania, USA, 1989.

33. Y. Liu, A. Vaughan, I. Hosier, C. Yeung and T. Andritsch, IEEE Conf. Electr. Insul. Dielectr. Phenom., 2015, 114-117.

34. I. Hamerton, Recent developments in epoxy resins, iSmithers Rapra Publishing, Shrophshire, UK, 1996. F. Alhabill, R. Ayoob, T. Andritsch and A. Vaughan, IEEE Trans. Dielectr. Electr. Insul., 2017, 24, 37393749.

36. I. Saeedi, A. Vaughan, T. Andritsch, L. Dissado and N. Chalashkanov, To be published, 2019.

37. J. K. Nelson, Dielectric polymer nanocomposites, Springer, New York, USA, 2010.

E. Riande and R. Díaz-Calleja, Electrical properties of polymers, Wiley, New York, USA, 2004. R. Casalini, D. Fioretto, A. Livi, M. Lucchesi and P. Rolla, Phys. Rev. B, 1997, 56, 3016.

Y. Wang, K. Wu, D. Cubero and N. Quirke, IEEE Trans. Dielectr. Electr. Insul., 2014, 21, 1726-1734. Y. Wang, D. MacKernan, D. Cubero, D. F. Coker and N. Quirke, J. Chem. Phys., 2014, 140, 154902. L. Xie, K.-Y. Chan and N. Quirke, Langmuir, 2017, 33, 11746-11753.

USA Pat., 3542684, 1970. USA Pat., 6696154, 2004. L. J. Bellamy, The Infra-red Spectra of Complex Molecules, Springer, London, Uk, 1975.

47. K. Neville and H. Lee, Handbook of epoxy resins, MacGraw-Hill, Michigan, USA, 1967.

48. B. Ellis, Chemistry and technology of epoxy resins, Springer, Hall, UK, 1993.

49. J. D. Menczel and R. B. Prime, Thermal analysis of polymers: fundamentals and applications, John Wiley \& Sons, USA, 2014.

50. M. Bakar, R. Duk, M. Przybyłek and M. Kostrzewa, J. Reinf. Plast. Compos., 2009, 28, 2107-2118.

T. V. Kosmidou, A. Vatalis, C. Delides, E. Logakis, P. Pissis and G. Papanicolaou, eXPRESS Polym. Lett., 2008, 2, 364-372.

52. P. Pissis and D. Fragiadakis, J. Macromol. Sci., Part B: Phys., 2007, 46, 119-136.

53. I. Hosier, A. Vaughan and S. Swingler, Journal of Materials Science, 1997, 32, 4523-4531. 
54. S. Dodd, J. Champion, Y. Zhao, A. Vaughan, S. Sutton and S. Swingler, IEE Proceedings-Science, Measurement and Technology, 2003, 150, 58-64.

55. V. Englund, R. Huuva, S. Gubanski and T. Hjertberg, IEEE Trans. Dielectr. Electr. Insul., 2009, 16, 14551461.

56. M. Jarvid, A. Johansson, V. Englund, A. Lundin, S. Gubanski, C. Müller and M. R. Andersson, J. Mater. Chem., 2015, 3, 7273-7286.

57. M. Jarvid, Ph.D, Chalmers University of Technology, 2014.

58. D. Cubero and N. Quirke, The Journal of chemical physics, 2004, 120, 7772-7778.

59. D. Cubero, N. Quirke and D. F. Coker, The Journal of chemical physics, 2003, 119, 2669-2679.

60. Q. N. Meunier M, J. Chem. Phys., 2001, 115, 28762881. 